\title{
Editorial
}

\section{The year 2013: nutrition at the top of the global agenda}

Nutrition has come a long way! Looking at the turn of events, no doubt the year 2013 will indeed be remembered as the Year of Nutrition. Going down memory lane, in 1933 nutrition hit the headlines of a major journal, The Lancet, as kwashiorkor, which was described in a small African country called Gold Coast, present-day Ghana $^{(1)}$. At the time the disease was thought to be associated with food, and in following years the provision of food and food aid became a major thrust of development agencies and governments, in an attempt to address malnutrition. With time, the situation began to unfold as we understood the complexities of the problem. Today we see nutrition with many faces: undernutrition, overnutrition, hidden hunger, open hunger, etc. Critically, during the formative years, in particular the first 1000 days (spanning conception to 24 months after birth), undernutrition can result in deep-rooted, irreversible damage to health, development, productivity and quality of life. Undernutrition affects a child's cognitive development and subsequently school performance. Undernutrition impairs human development and undermines national economic growth and development. Despite the harmful effects of undernutrition, it was marginalized. For decades, funding for nutrition was poor as it competed unsuccessfully with programmes on HIV/AIDS, malaria and other infectious disease. The fortunes of nutrition began to change with the advent of the Millennium Development Goals (MDG). It did not take long to realize that undernutrition was the most important constraint to achieving the $\mathrm{MDG}^{(2)}$, and indeed the mid-term evaluation of the MDG clearly showed that countries and regions with a high burden of undernutrition were much less likely to meet the MDG timeline of 2015.

In 2008, nutrition hit the headlines again. The Lancet Nutrition series of 2008 clearly presented the pathetic state of nutrition: fragmented and nobody's business ${ }^{(3)}$. The series of Lancet papers whipped global leaders into action. The Scaling Up Nutrition (SUN) Movement took up the challenge of coordinating efforts at the global level to support countries with high undernutrition burden to pay attention to this problem, and today thirty-five countries in this category have committed to address undernutrition. The last three years have seen some major shifts on the nutrition scene, especially at the global level. Many international organizations and governments have included nutrition strategies in their development plans.
The year 2013 has seen a line-up of high-level nutrition meetings: the UNICEF International Conference 'Against Child Undernutrition in sub-Saharan Africa'; the launch of the results of the new Lancet Nutrition series of $2013^{(4)}$ in London, Washington and Ethiopia; the UK Prime Minister's 'Nutrition for Growth' summit at the G8 meeting; the launch of the Amsterdam Initiative Against Malnutrition; the 20th International Congress of the International Union of Nutritional Sciences (IUNS); and the SUN session at the 67th UN General Assembly. Meetings have been held in many parts of the world to deliberate on how nutrition can be addressed in the post 2015 development agenda. Nutrition has never had this kind of attention at the global level. Addressing malnutrition has caught the attention of global leaders. To borrow the words of David Nabarro of the SUN Movement, 'we finally have the evidence right, we have the economics right, and the global leadership' to catapult us into action. The question to ask is, what does all this mean for the nutrition community?

As nutrition professionals and associations of nutrition professionals, we must realize that the momentum for nutrition is here and we must grab this unique opportunity and make an impact for nutrition. We must support the global effort by providing the evidence needed to ensure that nutrition indicators are included as specific targets in the post 2015 development agenda. The nutrition community must engage fully with the ongoing discussions around post 2015. We must realize that the malnutrition issue is very complex and cannot be tackled by only one group. We should be open and willing to build partnerships with relevant sectors (water, health, sanitation, governments) in a guided and coordinated manner to address the problem of undernutrition. As nutrition professionals, the global community will continue to depend on us to provide the evidence on what works. In this regard, our mentoring and capacity-building effort must be strengthened. The challenging nutrition landscape will demand more of us. Nutrition cannot remain at the top of the agenda if we do things as usual. We need to work to stay on top.

What are the skill sets and competencies needed to meet these new challenges? From the Lancet nutrition series 2013, the interventions needed to reduce undernutrition are known, but how to achieve impact at scale is still an issue begging for solutions. How do we build the right partnerships and borrow from the innovations of 
other disciplines such as information and communication technologies to advance nutrition? The cross-cutting nature of nutrition has substantially expanded the space for nutrition to work closely with other disciplines such as education, social protection, gender, agriculture, water and sanitation. For example, making agriculture more nutrition sensitive has become a topical issue for many development and international organizations.

As in-coming President, I believe that the vision of the IUNS, 'a world without malnutrition', remains unchanged. The need to build capacity to support the momentum is now more urgent than ever. This will be a priority for the in-coming Council. We recognize the need for collaborations in addressing nutrition issues. IUNS will use its global reach, through its Adhering Bodies, to provide countries with good nutrition information. IUNS will strengthen its collaborations with other scientific unions in working together to provide the evidence for scale-up.

The year 2013 presents a remarkable opportunity for nutrition. The dream of having a world without malnutrition can become a reality. We must grab this opportunity and make malnutrition history. The continued presence of nutrition issues on the global agenda will be dependent on results that this momentum brings. This is the time for nutrition, let us make it work!

Anna Lartey

President-Elect, IUNS

Department of Nutrition and Food Science

University of Ghana, Legon, Ghana

Email: aalartey@ug.edu.gh or aalartey@hotmail.com

\section{References}

1. Williams C (1935) A nutritional disease of children associated with a maize-based diet. Lancet ii, 1151-1152.

2. World Bank (2006) Repositioning Nutrition as Central to Development: A Strategy for Large-scale Action. Washington, DC: World Bank.

3. Morris SS, Cogill B \& Uauy R for the Maternal and Child Undernutrition Study Group (2008) Effective international action against undernutrition: why has it proven so difficult and what can be done to accelerate progress? Lancet $\mathbf{3 7 1}$, 608-621.

4. Black RE, Victora CG \& Walker SP for the Maternal and Child Undernutrition Study Group (2013) Maternal and child undernutrition and overweight in low-income and middle-income countries. Lancet (Epublication ahead of print version); available at http://dx.doi.org/10.1016/ S0140-6736(13)60937-X 